\title{
Implementing the Quality Startup Management System model in Hong Kong: a case study
}

\author{
Kim-Hung Lotto LAl ${ }^{1,2,3}$
}

\author{
Correspondence: lotto.lai@hkstp.org \\ ${ }^{1}$ Hong Kong Society for Quality, P.O. \\ Box 84375, Hunghom Bay Post \\ Office, Kowloon, Hong Kong \\ ${ }^{2}$ Hong Kong Science and \\ Technology Parks Corporation, 8/F. \\ Bio-Informatics Centre, 2 Science \\ Park West Avenue, Shatin, Hong \\ Kong \\ Full list of author information is \\ available at the end of the article
}

\begin{abstract}
The innovation and technology industries have become key areas to which the HKSAR Government is committed for advanced technology development and new economic driven. In order to nurture and support local technology startups grow and flourish successfully, HKSTP had signed a memorandum of understanding (MOU) with Hong Kong Quality Assurance Agency (HKQAA) to support incubation programmes through business matching and quality assurance mechanisms for startup companies. Hong Kong Society for Quality (HKSQ) was invited by HKQAA to be one of members in the advisory committee for this recognition scheme. Then, focus group was formed from different parties, including but not limited to incubatees, incubators, investors, HKSTP, HKQAA, HKSQ and other concerned stakeholders. This paper aims to introduce a systematic approach model named "Quality Startup Management System (QStarMS) Model" through literature review and analysis, focus group and case study. QStarMS integrated Business Side of startup using Business Model Generation/Canvas (BMG/C) and Management Side under ISO 9001:2015 Quality Management System, as well as, to simplify the model to fit startups requirements and overcome their limitations. Finally, we will report the recently progress of the QStarMS implementation through HKQAA Registration - Startups scheme.

Keywords: Quality Startup, ISO 9001:2015, Incubation Program, QStarMS
\end{abstract}

\section{Background}

Hong Kong Science and Technology Parks Corporation (HKSTP) is a statutory body inaugurated on 7 May 2001 by the HKSAR Government. Our vision is to create a vibrant innovation and technology ecosystem to deliver social and economic benefits to Hong Kong and the region; and our mission is connect stakeholders, facilitate knowledge transfer and nurture talents to accelerate technological innovation and commercialization. In order to achieve Science Parks vision and mission, HKSTP incubation programmes provide incubation services to assist technology startups in their vulnerable inception stages, enabling them to grow and flourish. Incubation Programme is split into three key areas, custom-made for startups in the fields of web and mobile technology, technology and biotechnology-Incu-App, Incu-Tech and Incu-Bio.

(c) The Author(s). 2017 Open Access This article is distributed under the terms of the Creative Commons Attribution 4.0 International License (http://creativecommons.org/licenses/by/4.0/), which permits unrestricted use, distribution, and reproduction in any medium, provided you give appropriate credit to the original author(s) and the source, provide a link to the Creative Commons license, and indicate if changes were made. 
Hong Kong Quality Assurance Agency (HKQAA), a non-profit-distributing organization, was established by the Hong Kong Government in 1989 to help industry and commerce in the development of quality, environmental, safety, hygiene, social and other management systems. Their missions are to promote management concepts in accordance with the applicable management system standards, to assist industry and commerce to implement relevant systems and to deliver world-class conformity services.

Hong Kong Society for Quality (HKSQ) as professional body has formed since 1986. Its members includes executives, managers, engineers, industry practitioners, academics, students and those who are interested in quality engineering, management and associated disciplines and practices in organizations of respective industries in Hong Kong and abroad. HKSQ is one of advisory bodies to share knowledge and expertise for developing the Quality Startup Management System so as to fulfill the 2nd core aspect "Recognition for Innovation and Technology Startup Company" through the Quality Startup Recognition Scheme for all incubatees under the incubation programmes in HKSTP.

In order to enhance technology startup growth in Hong Kong, HKSTP and HKQAA had signed a memorandum of understanding (MOU) in March 2015. It aims to support incubation programmes with a mutual understanding for the following four core aspects:

1. Business Matching,

2. Recognition for Innovation and Technology Startup Company,

3. Community for Innovation and Technology Professional, and

4. Promoting Management Concepts and Knowledge Transfer.

After that HKQAA has developed the startup registration scheme to provide recommended practices for the startups to systematically manage their operations, particularly in quality, financial and information security aspects [1]. The scheme achieving performance objectives by defining and monitoring the measurable targets and goals are shown as follows:

1. Reducing business risks by identifying and managing the risks

2. Continual improvement of operations

3. Demonstrating management competence

4. Enhancing business partners' confidence

\section{Case description}

The Quality Startup Recognition is based on HKQAA Registration-Startup as the foundation scheme to achieve the objectives of MOU between HKSTP and HKQAA for business matching included HKQAA key customers, investors (e.g. Member in Hong Kong Business Angel Network (HKBAN)) and other startups in other coworking spaces under TechnoPreneur Partnership (TPP) program. The overall idea is shown in Fig. 1. Quality Startup will be considered in Product and Business Development, Technology and Quality Management, as well as, Financial Management. 


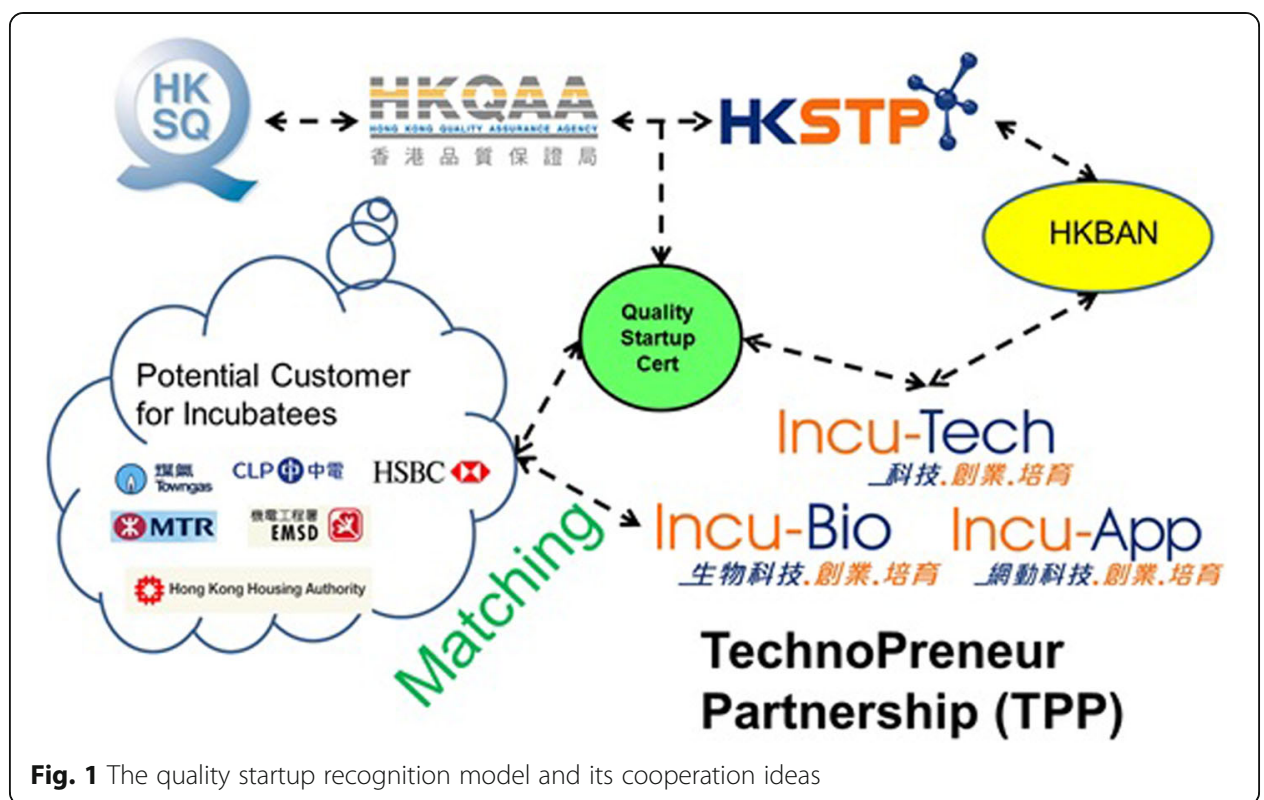

\section{Literature review}

\section{Business model canvas}

A business model is a holistic concept embraced elements of pricing, mechanisms, customer relationships, partnering and revenue sharing, etc. Every startup would like to join HKSTP Incubation Program must prepare a viable business model. Business Model Canvas (BMC) developed by Osterwalder and Pigneur [2] included four areas of company, namely Customer Interface, Value proposition, Infrastructure Management and Financial Aspects, which is employed by Quality Startup Management System

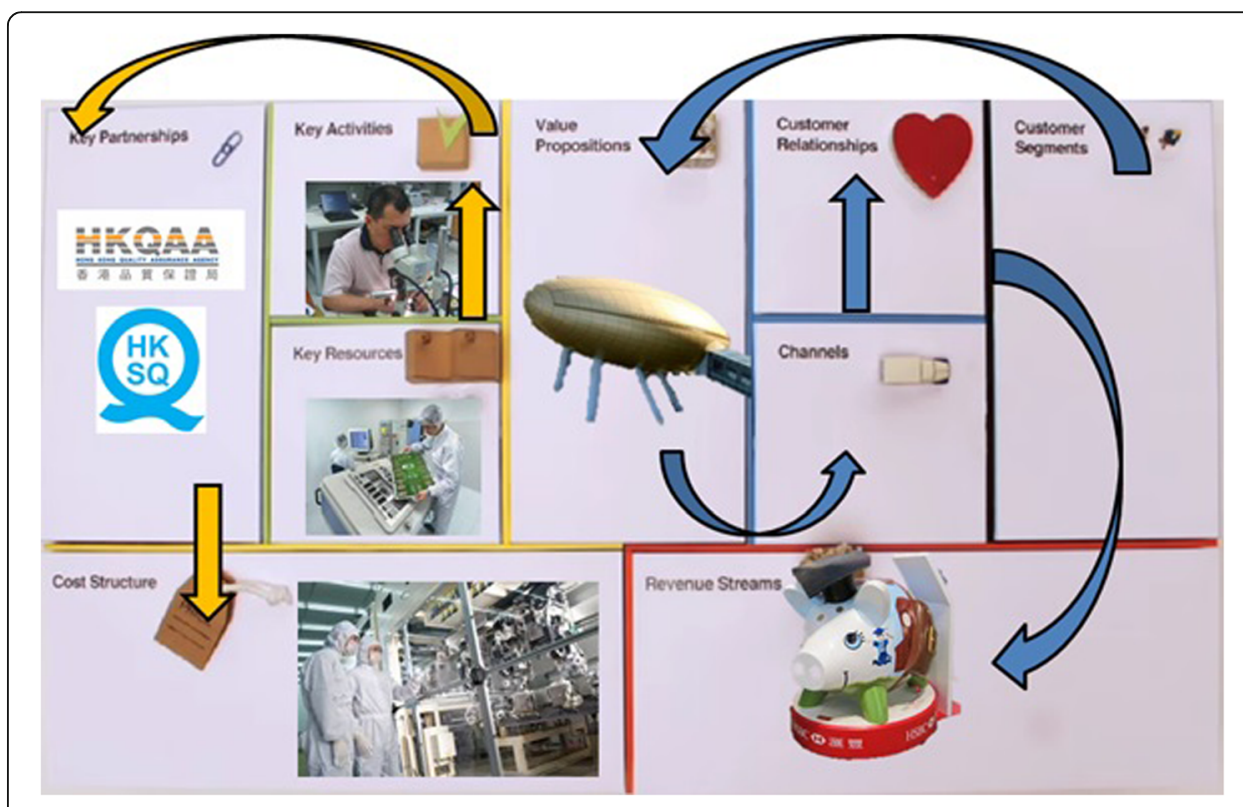

Fig. 2 The business model canvas with the nine building blocks (e.g. incubation programme) 
(QStarMS) model [2]. These four areas are further divided into a set of nine interlinked building blocks namely Customer Segments (CS), Value Proposition (VP), Channels $(\mathrm{CH})$, Customer Relationships (CR), Revenue Streams (RS), Key Resources (KR), Key Activities (KA), Key Partnerships (KP) and Cost Structure (CT). The framework of BMC using incubation program in HKSTP as sample demonstrated in Fig. 2.

Osterwalder and Pigneur [2] and Miki Imazu [3] described the model starting from Customer Segments (CS) [2, 3]. CS identifies the different groups of people/ organizations which an enterprise aims to reach and serve. From CS moving to Value Proposition (VP), VP defines a bundle of products and services which would create value for a specific CS. It needs a Channel $(\mathrm{CH})$ to provide means for company to communicate with and reach its CS to deliver VP. Further, different types of relationships of Customer (CR) a company shall be built with specific CS. Consequently, Revenue Streams (RS) indicates the value a company generating from each CS, i.e. cost subtracted from revenues. This route is called "Customer Value Infrastructure".

Another route named "Business Value Infrastructure" starts from Key Resource (KR) that illustrates the most critical assets required to support Key Activities (KA) which is the most important operations a company must do to make its business model work (value-added process). KA can be enhanced by Key Partnerships (KP) which provides a network of suppliers and partners. Finally, Cost Structure (CT) is all costs incurred to operate a business model that should be considered.

\section{ISO 9001:2015 quality management system}

Quality management has a long history. Its evolution took place during the Industrial Revolution when traditional inspection role was the starting point, and continued through quality control, quality assurance, to Total Quality Management (TQM) and so on. The ISO 9001 Quality Management System (QMS) standard is widely accepted around the world. ISO 9001 QMS model uses a process approach and its advantages are:

a) Understanding and meeting customer requirements,

b) Considering processes in terms of added value,

c) Assessing results of process performance and effectiveness

d) Continually improving processes based on objective measurement.

The new version of ISO9001:2015 is established based on PDCA cycle (Fig. 3) and Annex SL-High Level Structure (HLS) that is the common framework for all ISO management systems. There are ten clauses of standard (Table 1). The implementation of QMS begins from clause 4 (Context of Organization) that organization requires to determine external and internal issues that are relevant to its purpose (or intended outcome).

1. Planning phase: clause 5-Leadership and clause 6-Planning stress on involvement of top management and understanding of the major risks associated with each process through the planning on addressing risks and opportunities. 


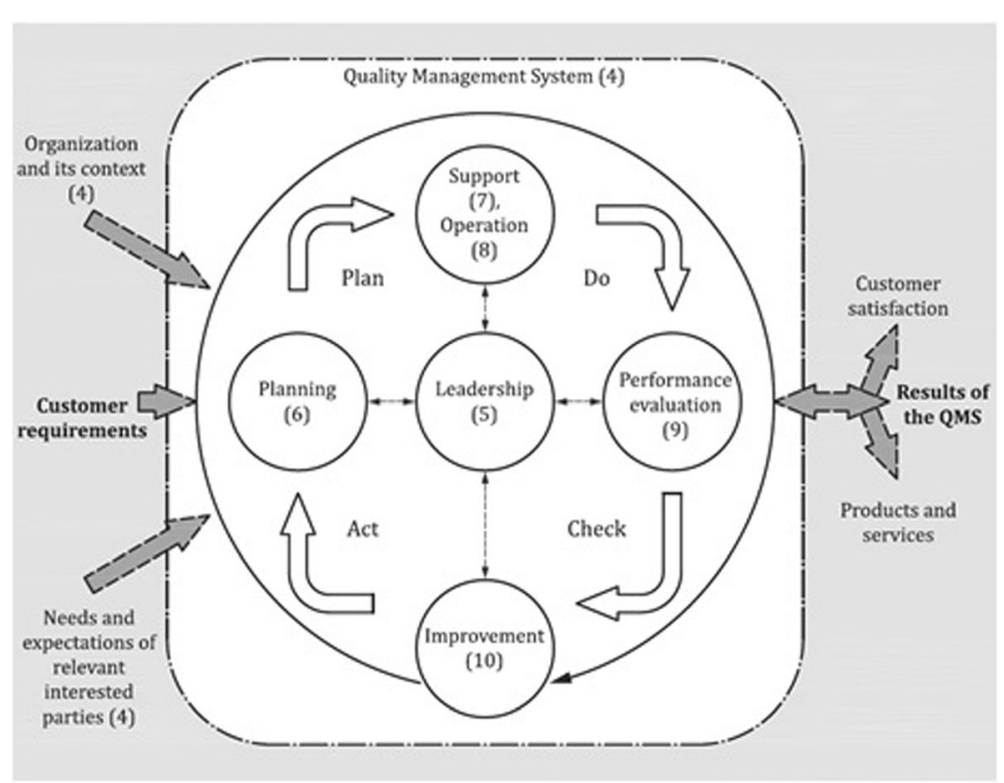

Fig. 3 The quality management system model (ISO 9001:2015)

2. Do phase: clause 7-Support and clause 8-Operation determine and provide the necessary resources to execute the plan and to meet customer requirements.

3. Check phase: clause 9-Performance Evaluation defines requirements for monitoring, measurement, analysis and evaluation, as well as, Internal Audit and Management Review.

4. Act phase: clause 10-Improvement gives a new manner to put preventive actions into practice (where preventive action was removed in the new version of ISO 9001:2015), i.e. incorporated preventive actions in QMS through risk assessment.

Table 1 Key clauses of ISO 9001:2015

\begin{tabular}{|c|c|}
\hline Clauses of ISO 9001:2015 & \\
\hline 2. Normative References & 3. Terms and Definition \\
\hline 4. Context of Organization & 7. Support \\
\hline $\begin{array}{l}\text { - Understandingthe organization and its context } \\
\text { - Needs and expectations of interested parties } \\
\text { - Determining the scope } \\
\text { - Management System }\end{array}$ & $\begin{array}{l}\text { - Resources } \\
\text { - Competence } \\
\text { - Awareness } \\
\text { - Communication } \\
\text { - Documented information }\end{array}$ \\
\hline 5. Leadership & 8. Operations \\
\hline $\begin{array}{l}\text { - Leadership and commitment, Policy } \\
\text { - Roles, responsibility and authority }\end{array}$ & - Operation planningand control \\
\hline 6. Planning & 9. Performance Evaluation \\
\hline $\begin{array}{l}\text { - Actions to address risks \& opportunities } \\
\text { - Objectives and plans to alchieve them }\end{array}$ & $\begin{array}{l}\text { - Monitoring, measurement, analysis \& evaluation } \\
\text { - Internal audit } \\
\text { - Management review }\end{array}$ \\
\hline 10. Improvement & \\
\hline $\begin{array}{l}\text { - Non-conformity and corrective action } \\
\text { - Continual improvement }\end{array}$ & \\
\hline
\end{tabular}




\section{HKSTP incubation milestone assessment}

HKSTP Incubation Programmes have quality assurance mechanism to guide and assist startups through regularly milestone assessments. When startups apply for the incubation programmes, they are required to submit business plan with key milestones, follow their plan and carry out their product and business development. HKSTP incubation team will check their performance according to the submitted plan through milestone assessments. HKSTP has three incubation programmes with different incubation period, i.e. Incu-App (18 months), Incu-Bio ( 4 years) and Incu-Tech (3 years). The assessment criteria among Incu-App, Incu-Bio and Incu-Tech are shown as Table 2.

Incu-App is focused on Apps, web and mobile technology. The product life cycle is short and highly requested on time to market. Therefore, the milestone assessment will be performed in the 3rd month after admission of the programme. Then, the sequence of assessment will be 6th month and 12th month. If startups performances are below the standards, they need to join a Performance Improvement Plan (PIP). For Incu-App, it will be added one more assessment in the 9th month if they under PIP in previous milestone assessment.

Incu-Tech is focused on different technology such as electronic- or internet-based platform development (except Apps programming and Biotechnology). The requirement level is higher than Incu-App. Within 3 years incubation period, there are five milestone assessments and each assessment per 6 months as the 6th, 12th, 18th, 24th and 30th month (Fig. 4).

Incu-Bio is focused on biotechnology such as pharmaceutical, health care, elder/ ageing service, etc. It is the longest programme up to 4 years among HKSTP incubation programmes. Within 3 years incubation period, there are seven milestone assessments and each assessment per 6 months as the 6th, 12th, 18th, 24th, 30th, 36th and 42nd month.

Table 2 Comparison of milestone assessment criteria among Incu-App, Incu-Bio and Incu-Tech

\begin{tabular}{ll}
\hline Incu-Tech and Incu-Bio & Incu-App \\
\hline Product Development Progress & \\
- Design Work & - Design Work \\
- Design for Manufacturing & - Technical Testing \\
- Testing & - Usability Testing \\
- Prototype/Sample & - Product Launch \\
- Product Demonstration & \\
- Trial Client/Pilot Site & \\
HKSTP Service Utilization & \\
- Laboratory Service & \\
- Assistant Funding & \\
- Industry and University Collaboration, etc. & \\
Business Development Progress & \\
- Business Partnership & \\
- Sales and Marketing Activities & - Strategic Partners/Business Collaboration \\
- Award Application & - Promotion and Traffic Driving \\
- Number of Client & - Award Application \\
- Patent/Trademark Application & - Download Rate \\
- Funding Activities & - Capitent/Trademark/Design Registration \\
- Headcount & - Headcount \\
- Sales Revenue & - Sales Revenue \\
\hline
\end{tabular}




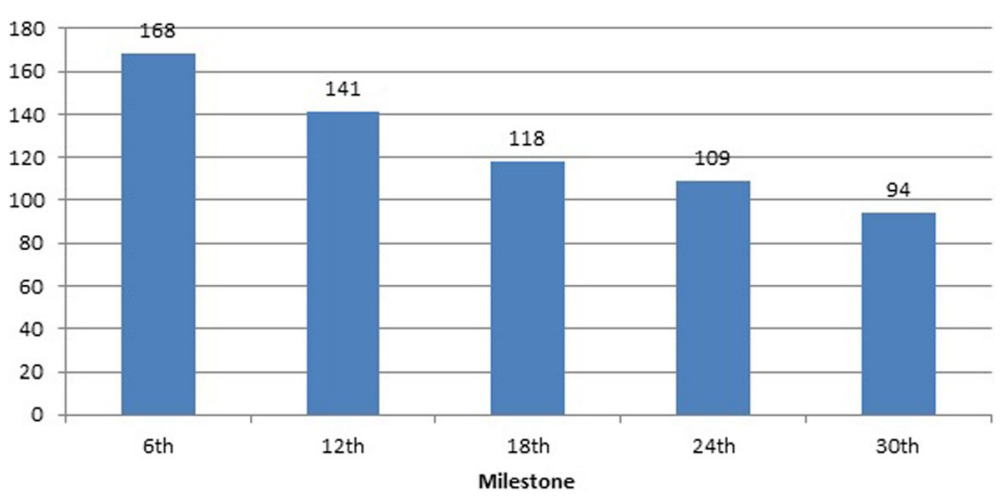

Fig. 4 No. of company completed each IncuTech milestone assessment

\section{Limitations identified from literature review and statistics Limitations of Business model canvas and ISO 9001:2015}

Startup employed BMC over the world because of three features included "Simplicity", "Practice-orientation" and "Plug-and-Play principle" [4]. Even though BMC is a very useful conceptual tool for startups to present the value creation, systematic description of the mechanism of interaction with partner business, as well as, converting technological developments into economic benefits, some neglected items are showed as follows $[5,6]$ :

i) It excludes organization's strategic purpose (only financial success drive startup)

ii) It excludes a notion of competition

iii) It mixes levels of abstraction

Another limitation observed was lack of systematic requirement for implementing such BMC after startup adopted. Moreover, nine boxes could be consolidated into four large groups (meta-concept) as a mind map of BMC which could be modified for Quality Startup Management System Model development [7]. Therefore, Gavrilove suggested Mind Map BMC consolidated into four groups below:

i) Products (contain-KA and VP)

ii) Customers (contain- $\mathrm{CR}, \mathrm{CH}$ and $\mathrm{CS}$ )

iii) Environment (contain-KP and KR)

iv) Finance (contain-CT and RS)

Eventhough ISO 9001 Quality Management System is systematic process approach model, but the difficulties on implementation of ISO 9001 in startups were pointed out by Zeng et al. [8] and Gotzamani [9], some critical barriers to implement ISO 9001 standard were identified as follows $[8,9]$ :

i) Limitation on Human Resource (few key members in startup only)

ii) Limitation on Knowledge of QMS (no training in the beginning of startup business)

iii) Inadequate Management Commitment (Product and Business Development (or Survive) is the first priority.) 
iv) Inadequate Attitude Towards Quality (delivery first)

v) Heavy Documentation Requirement (No practice on traceability)

vi) Over-expectation on ISO 9001 Standard (What its value on startup in terms of business?)

vii) Short-sighted Goal for "Getting Certified” (access government or big company's tender list)

viii) Unrealistic Requirements and Ritualistic Implementation

Therefore, seldom startups implement ISO 9001 successfully and get their value after heavier resources input (including HR, Knowledge, Time and Money) to establish and implement the QMS.

\section{Limitation from HKSTP milestone statistics}

HKSTP regular incubation milestone assessment for 94 startup companies, they completed all milestone assessment within 3 years (Fig. 4), under Incu-Tech schemes have assessed and the following characteristics are observed.

For Product Development, it observed that (Fig. 5):

i) Most of startups had planned and met their product development under their milestone.

ii) About $50 \%$ of startups did not consider "Design for Manufacturing". It is probably the IT dominant startups in the scheme.

iii) More than $80 \%$ of startups planned to employ "HKSTP Service Utilization" so as to enhance their product development.

For Business Development, it observed (Fig. 5):

i) Difficulty to achieve the "Headcount" and "Sales Revenue" they planned in the last three milestones (on 18th, 24th and 30th month).

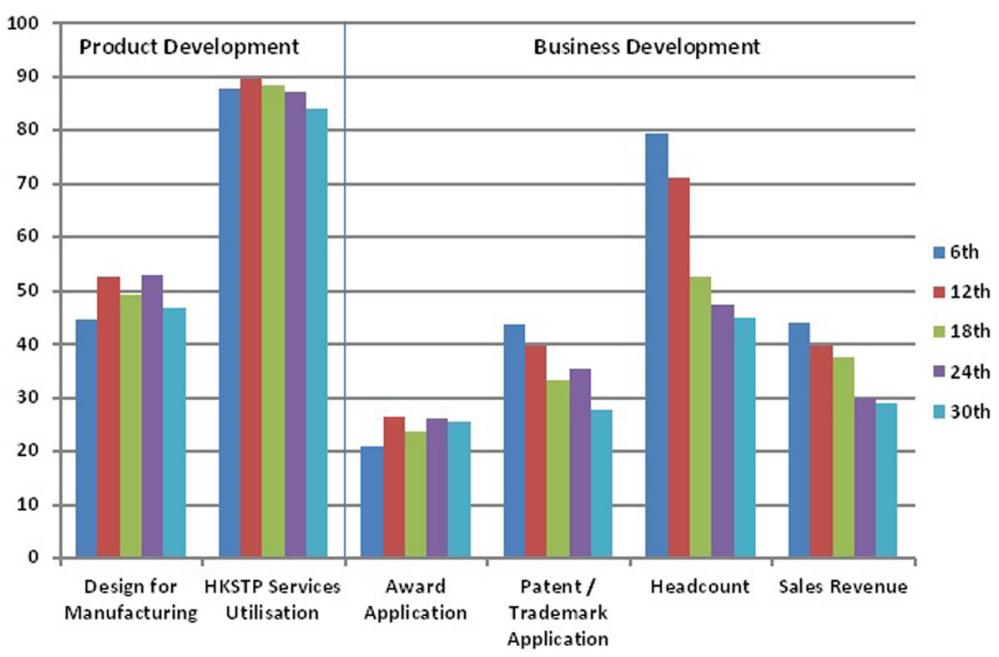

Fig. 5 Statistics of some features on IncuTech milestone assessments 
ii) More than $60 \%$ of startups without planning for Award Application

iii) About 50\% startups did not consider "Patent/Trademark Application" and "Funding Activities".

Based on the above limitations, a simplified HKQAA Startup Assessment Checklist (25 questions) is employed for registration scheme. For Product and Business Development, it depends on HKSTP regular incubation milestone assessment. Employing this Startup assessment checklist, startups are required to demonstrate they had implemented the requirements with records or relevant documentation. Most startup had not experience on implementation of the management system (e.g. ISO 9001, ISO 27001, etc.) so that it foresees some difficulties for employing this checklist and summarized as follows:

i) Without systematic model for startup to implement to achieve these requirements.

ii) Without a stepwise framework for QStarMS to follow.

iii) Without guideline for implementation, especially on three key areas control (Product, Finance and InfoSec).

HKQAA assessment checklist for startup

HKQAA had proposed a registration handbook with assessment checklist for startups established for not more than 5 years. The checklist focuses mainly on General, Quality Control, Financial Control and Information Security Control (See Table 3) with 25 questions. Auditor will register the operations of participated startups' current management system through inspection with Yes, No or Not Applicable.

\section{Development of Quality Startup Management System (QStarMS) Model Combination among BMC, ISO 9001 QMS, HKSTP and HKQAA assessment requirements} After reviewed BMC, ISO 9001:2015, HKSTP Incubation Milestone Assessment and HKQAA Assessment Checklist (25 questions), the proposed QStarMS Model is created as Fig. 6 by taking into account all features of BMC, PDCA, HKSTP Milestone Assessment and HKQAA Checklist [10-12]. Since different management system integration especially Total Quality Management (TQM) had been studied [13-15], most of them employed Plan, Do, Check, Act (PDCA) approach as the foundation. Therefore, a holistic simply model is formed for startup as below.

The backbone of QStarMS Model is based on Plan-Do-Check-Act (PDCA) cycle and then integrated our existing approach step by step which starts from "Value Proposition and Core Asset" to "Customer".

\section{Step 1: Plan phase}

It considers "Customer Value Infrastructure" from Customer Segments (CS) to Value Proposition (VP) to Channels $(\mathrm{CH})$ and then to Customer Relationships (CR); where Revenue Streams (RS) belongs to Finance aspect under Check Phase. CS, CR and $\mathrm{CH}$ are classified as Customer aspects.

\section{Step 2: Do phase}

It considers "Business Value Infrastructure" from Key Resources (KR) to Key Activities (KA) and then to Key Partnerships (KP); where Cost Structure (CT) also belongs to 
Table 3 HKQAA quality startup recognition scheme-registration handbook appendix A

\begin{tabular}{ll}
\hline Three focus area & Checklist topic \\
\hline General & 1. Establishing measurable performance objectives \\
2. Reviewing the achievements of performance objectives \\
3. Corrective and preventive action plan if deviated \\
4. Contingency plan to resume its operation \\
5. Identification of customer requirements for product/sendee \\
6. Review and confirm requirements \\
7. Control processes for production, delivery and after sales sendees \\
8. Review compliance to established control processes \\
9. Resources—-Identify staff competence requirement \\
10. Resources—Ensure staff who fulfill competence requirement \\
11. Resource-Identify material, equipment, machine and infrastructure needs \\
12. Resources—Confirm/verify those specifications \\
13. Resources—Monitoringthose fit for use (e.g. PM. Calibration) \\
14. Design—Development plan for product/sendee \\
15. Design—Specifications from customer requirement \\
16. Design—Review its design and development progress \\
17. Design—Verify the final designs of product/sendees \\
18. Budget plan for its operations \\
19. Monitor the actual cost against the budget \\
20. Mitigation measures if undesirable trends \\
21. Procurement procedure \\
22. Contractual agreements and responsibility definition \\
23. Classify information assets and implement access control \\
24. Information backup \\
25. Information Disposal \\
Financial Control
\end{tabular}

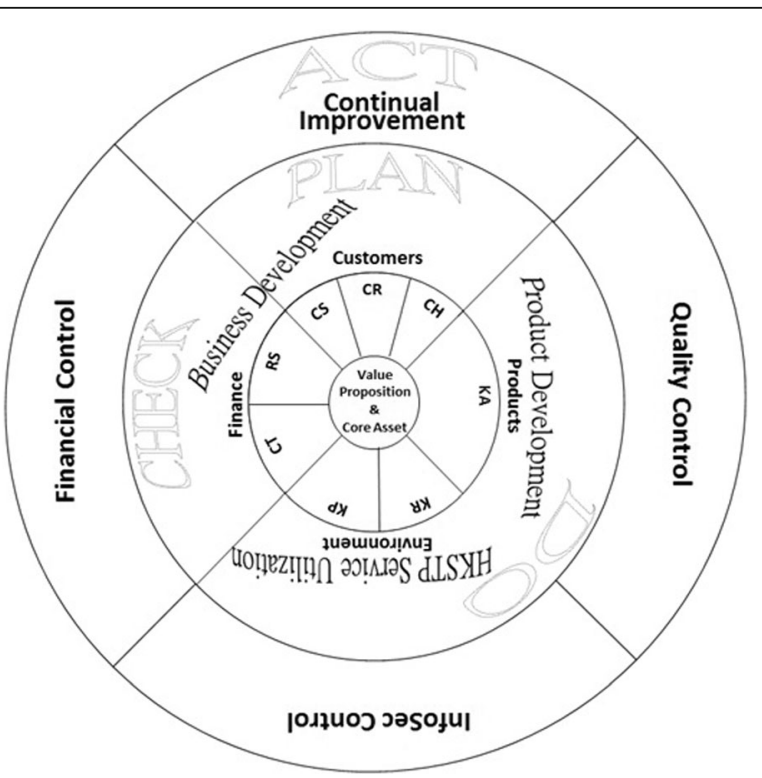

Fig. 6 The quality startup management system model (QStarMS Model) 
Finance aspect under Check phase. KA is classified as Products aspect; KR and KP are classified as Environment aspects.

In Do phase-Products aspect, both HKSTP incubation milestone assessment's "Product Development" and HKQAA assessment checklist for startup "Quality Control" are integrated to help startup to develop their products/services. It is a reasonable integration for product design and prototype development based on Tables 2 and 3.

In Do phase-Environment aspect, it related to "HKSTP Service Utilization" under HKSTP incubation milestone assessment and "InfoSec Control" under HKQAA assessment checklist for startup. HKSTP Service Utilization included Laboratory Service, Assistant Funding and Industry and University Collaboration which provide a good startup environment for their product prototype development on KR and KP. During prototype design, we observed that information security management is very important and most startup neglected. Therefore, "InfoSec Control" requirements under HKQAA assessment checklist for startup are integrated into QStarMS model.

\section{Step 3: Check phase}

In Check phase, it usually considers startup financial performance. Therefore, the finance aspect included Cost Structure (CT) and Revenue Streams (RS) to be assessed. We observed that many startup milestone assessments in Headcount and Sales Revenue did not meet as they planned (Fig. 5). Therefore, HKSTP Business Development supports are across the Check Phase to Plan Phase that work as Continual Improvement. HKQAA assessment checklist for startup "Financial Control" is integrated into Check Phase of QStarMS aims to monitor their budget plan, cost against the budget, procurement control and mitigation measures.

\section{Step 4: Act phase}

After Plan, Do and Check Phase, the assessment results obtained from HKSTP Incubation Milestone Assessment and HKQAA Assessment Checklist that would be pointed out as "Area for Improvement (AFI)" for startup consideration and improvement on four aspects included Customers, Products, Environment and Finance.

\section{Discussion and evaluation}

\section{Implementation}

After signed Memorandum of understanding (MOU) with HKSTP in May 2015, HKQAA has developed the startup registration scheme with HKSTP and HKSQ in the coming year. Finally, HKQAA defined 25 questions covered "General (Q1-Q4)", "Quality Control (Q5-Q17)", "Financial Control (Q18-Q21)" and "Information Security Control (Q22-Q25)" in the Registration Handbook Appendix A. We decided to select potential incubatees in HKSTP for pilot program. Those potential incubatees had passed HKSTP milestone assessment with good evaluation results and highly potential for acceleration. The promotion briefings and workshops had performed in the beginning of 2016. The schedule of pilot run of Quality Startup Recognition is shown in Table 4.

The briefing session is mainly explained the program concept and benefit for assisting startup to build their management competence and to create opportunity for their 
Table 4 HKQAA \& HKSTP Pilot Program of Quality Startup Recognition Scheme

\begin{tabular}{llll}
\hline Date & Items & $\begin{array}{c}\text { Incubatees } \\
\text { participated }\end{array}$ & Remark \\
\hline 25 Jan 2016 & The 1st Briefing Session & 10 & HKQAA and HKSTP \\
25 Feb 2016 & The 1st QStartup Workshop & 7 & HKSTP and HKQAA \\
18 Mar 2016 & The 2nd Briefing Session & 8 & HKQAA and HKSTP \\
23 Mar 2016 & The 2nd QStartup Workshop & 4 & HKSTP and HKQAA \\
30 Mar 2016 & HKSTP Incubation Program Graduation & 9 & HKSTP announce pilot program \\
& Ceremony & & HKQAA formal launch the \\
& HKQAA Symposium 2016 & 11 & registration scheme \\
\hline
\end{tabular}

business development. The workshop was arranged by HKSTP and demonstrated how to reply 25 questions by using HKSTP Laboratories as example. After that we recruited 11 incubatees who are interested in joining the scheme. Those incubatees have got good performance under HKSTP milestone assessment and then nominated for HKQAA Registration-Startup scheme. They were guided to follow QStarMS PDCA cycle before and during audit period.

The HKQAA Registration-Startup separates three grades and there are "Platinum", "Gold" and "Regular". The pilot program has 11 incubatees participated and 8 of them are assessed before HKQAA Symposium. The results are shown as follows:

- Registered Platinum Startup: 4

- Registered Gold Startup: 2

- Registered Startup: 2

- Waiting for assessment: 3

After the implementation, we got startups' feedback and comments that most of them satisfy the scheme during the post audit evaluation. The post audit customer satisfaction questionnaires included audit arrangement, process, report and team knowledge, as well as conclusion. The rating is from 1 to 7 (from Strongly Disagree to Strongly Agree). Over 95\% rated mark above 6. Most of them indicated the scheme helped their continual improvement.

\section{Conclusions}

We believe the business opportunity and management skill level, as well as, survival rate will be enhanced if startups employ Quality Startup Management System (QStarMS) Model and have registration under HKQAA-HKSTP Startup Recognition Scheme. QStarMS model consists of BMC startup basic business function, key elements of ISO 9001, concerns of Information Security (InfoSec) control and the core value of all management system, i.e. continual improvement. The model will help to overcome the difficulties and limitation for startups' business and product development, and to enhance their management skill level. The next step is to enlarge the participants and to arrange more business matching, as well as, contacting with investor (e.g. HKBAN) to let them know the quality of our registered startups. We have 
planned to prepare some documents template in order to facilitate the startup and invite some experts or specialist to sharing more on IP registration, service agreement preparation. The new round of business matching activities between HKSTP and HKQAA have launched in 2017.

\section{Abbreviations}

BMG/C: Business Model Generation/Canvas; HKBAN: Hong Kong Business Angel Network; HKQAA: Hong Kong Quality Assurance Agency; HKSQ: Hong Kong Society for Quality; HKSTP: Hong Kong Science and Technology Parks Corporation; MOU: Memorandum of understanding; QStarMS: Quality Startup Management System

\section{Acknowledgements}

HKSTP Incubation Program team provided raw data.

\section{Funding}

NA.

Availability of data and materials

Stated in the reference; Raw data from HKSTP Incubation Program is not exposure.

\section{Authors' information}

Lotto Lai is Quality Manager in HKSTP and responsible to the MOU between HKSTP and HKQAA. He is former chairman of HKSQ and Adjunct Professor of SEEM Dept., City U. Therefore, Lotto is key person to implementing the QStarMS in HKSTP startup companies with society and university support.

\section{Competing interests}

The author declares that he has no competing interests.

\section{Publisher's Note}

Springer Nature remains neutral with regard to jurisdictional claims in published maps and institutional affiliations.

\section{Author details}

${ }^{1}$ Hong Kong Society for Quality, P.O. Box 84375, Hunghom Bay Post Office, Kowloon, Hong Kong. ${ }^{2}$ Hong Kong Science and Technology Parks Corporation, 8/F., Bio-Informatics Centre, 2 Science Park West Avenue, Shatin, Hong Kong.

${ }^{3}$ Department of Systems Engineering and Engineering Management, City University of Hong Kong, Kowloon, Hong Kong.

Received: 2 February 2017 Accepted: 8 June 2017

Published online: 14 July 2017

\section{References}

1. HKQAA News (2016) HKQAA Hong Kong Registration—Start-ups Kicked off at the HKQAA Symposium 2016 https://Inkd.in/fkW2bVg

2. Osterwalder A, Pigneur Y (2010) Business model generation: a handbook for visionaries, game changers, and challengers. John Wiley \& Sons, Hoboken NJ

3. Imazu M (2013) ZUKAl business model generation workbook. Shoeisha Co., Ltd

4. Ching HY, Fauvel C (2013) Criticisms, variations and experiences with business model canvas. Int J Small Busi Entrepreneur Res 1(4):18-29

5. Kraaijenbrink (2012) Three shortcomings of the Business Model Canvas. Kraaijenbrink Training \& Advies. Retreved October 18, 2013, from http://kraaijenbrink.com/2012/07/shortcomings-of-the-business-model-canvas/

6. Mäkelä, Otto \& Pirhonen, Veikka (2011) "The Business Model as a Tool of Improving Value Creation in Complex Private. Service System —Case: Value Network of Electric Mobility" $21^{\text {st }}$ International RESER Conference, http://www. reser.net/materiali/priloge/slo/mkel_et_al.pdf

7. Gavrilova T, Alsufyev A, Yanson AS (2014) Modern notation of business models: visual trend. Foresight-Russia 8(2):56-70

8. Zeng SX, Tian P (2007) Overcoming barriers to sustainable implementation of the ISO 9001 system. Manag Audit J 22:244-254

9. Gotzamani KD (2005) The implications of the new ISO 9001:2000 standards for certified organizations. Int J Product Perform Manag 54(8):645-657

10. Lai LKH, Chin KS, Tsang AHC (2009) Integration of Quality Management System and Information Security Management System—HKSTP implementation case. Proceedings CD-ROM of The seventh ANQ Congress, paper id: HKO2.

11. Lai LKH, Chin KS, Tsang AHC (2011) Integrated Laboratory Management System (ILMS) Model—HKSTP implementation case. The ninth ANQ Congress, paper id: 28-A-01.

12. Lai LKH, Chiang MMP (2015) Quality Startup Management System Model. International Academy for Quality - World Quality Forum, Stream D, D2 session.

13. Chin KS, Dale BG (2000) A TQM implementation framework for Hong Kong manufacturing industries. City University of Hong Kong, http://www.hksq.org/Booklet_TQM_implementation_framework.pdf

14. Pun KF, Lau CW (2003) Integration of total quality management and performance measurement in government departments: an empirical study in Hong Kong. Int J Bus Perform Manag 5(4):316-335

15. Lalla TRM, Lewis WG, Pun KF, Chin KS, Lau HCW (2003) Manufacturing strategy, total quality management and performance measurement: an integrated model. Int J Manuf Technol Manag 5(5-6):414-427 